\title{
Women's Community Participation Levels in Community-based Health Programs Regarding Breast Cancer Prevention in Metropolitan Tehran, Iran
}

\author{
Maryam Ahmadian, Ma'rof Redzuan (Corresponding author), Zahid Emby \& Asnarulkhadi Abu Samah \\ Department of Social and Development Sciences \\ Faculty of Human Ecology, Universiti Putra Malaysia \\ 43400, UPM Serdang, Selangor, Malaysia
}

Tel: 60-3-8946-7064Ｅ-mail: marof@putra.upm.edu.my

\begin{abstract}
Iran has recognized community participation in health research as an essential part of the country's health system. Community participation is focused on the prevention of communicable diseases, mother and child care, family planning and first aid. Besides, the issues of health education and community participation regarding breast cancer prevention are not similar to other activities included into primary health care services, such as family planning in Iran. Within this context, increasing the participation of women community regarding breast cancer prevention, through recognized channels such as health workers, community leaders, health educators, health care professionals, teachers and women volunteers should be given high priority at on the community, district, province and national levels. Local community participation in health and wellbeing is strongly supported as a fundamental element to development. Thus, the objective of the current study was to identify the levels of women's community participation in community-based program on breast cancer prevention. The study involves a cross sectional survey of women who have participated in mammography in the last two years $(n=86)$. The actual level of community participation was assessed based on Rifkin's perspective. Using five levels of participation in health programs by Rifkin (1991), the study examined the feasibility of public participation in health and relieves effort on breast cancer prevention based on local community participation. The study assessed the level of women's community participation in breast cancer prevention programs, due to the importance of women's role in the community. Women's community participation in breast cancer prevention is currently insignificant. The maintenance of benefits and activities denotes sustainability in community -based health programs. More researches are therefore needed to understand the role of local communities in the development of community- based health programs.
\end{abstract}

Keywords: Breast cancer prevention, Community participation, Community participation levels, Community-based program, Sustainable development

\section{Introduction}

Following the Alma-Ata deceleration (1978), policy makers have found community participation as a necessary prerequisite in the development of local health services, interventions, community mobilizations and public participation in health programs. Local communities became actively involved in the health activities and decision that affected their health. However, the lack of a framework for community participation could be argued by scholars who declared participation from Alma Ata. As a result those responsible for health programs mainly policy makers, planners and professionals envisage community participation from a vague perspective, hence the difficulty in developing health care (Rifkin, 1996). People particularly women are the most important participants in community-based participatory approach. They have an important role in the Women Health Volunteers program. Therefore, understanding the role of women especially in local community participation mainly in breast cancer prevention is an important attempt. Thus, in this study attempt was made to explore the levels of women's community participation in community based programs regarding breast cancer prevention.

\section{Literature review}

The literature review regarding community participation in health programs, particularly community-based programs aims to review community activities related to health issues. However, there is a lack of quantitative studies to measure community participation levels in health programs. Previous researchers have proposed that participation exists at a series of levels ranging from information sharing to true empowerment. Although 
community participation was used in the original Alma-Ata document of 1978, however, community involvement is now the preferred term because participation may simply reflect a response. According to Myezwa, (2003), community involvement is preferred when community participation is difficult in health care because this term focuses on participation as a passive response.

Community participation is a means, or a process, leading to improved health status (Cohen \& Syme, 1985; House, Landis, \& Umberson, 1988). Moreover, participation is one of the elements of development (Stone et al. 1992). In relation to this, Boyce (2003) studied community participation in the public health segment. Other researchers argue that participation is a valued end, or health outcome, in itself (Oakley, 1989; Vuori, 1986). Existing literatures identified three functions of community participation linked to means/ends goals (Cohen \& Uphoff, 1980; Oakley, 1991; WHO, 1991; Stone, 1992; Mikkelsen, 1995; Zakus, 1998).

The logic of public participation in health programs is underpinned in two basic fundamentals. The first one presupposes health as a total well-being is not only of individuals, but also for communities, and the second stresses health care as a responsibility of the people themselves, not only of trained professionals (Raeburn and Rootman 1998). However, participation is influenced by the political, social, economic and cultural environment, in line with the degree to which individuals and communities are empowered.

To explain the levels of women participation in breast cancer prevention programs, the present study disputed Rifkin (1991) views on participation levels in community-based program to assess the actual levels of participation in the study population. As Rifkin (1991) claimed that community participation in health programs is ideal, but high levels of participations is hardly ever achieved. It means projects related to health need to specify, practically what levels of participation must be achieved.

Rifkin (1991) indicated five levels of participation:

(1) Health benefits where communities are only utilizing health services or education.

(2) Program activities that there is local contribution of labour, land or money.

(3) Implementation that focuses local peoples managerial responsibilities and decides how activities are to be carried out.

(4) Monitoring and evaluation of program activities.

(5) Deciding what program activities should be carried out with outside support in terms of resources and knowledge (Figure 1).

Kapiriri (2003) studied community participation in health planning in Uganda at district levels based on Rifkin (1991) perspective regarding levels of participation. Furthermore, the author noted that there are no decision-making, monitoring, evaluation and implementation levels in public participation in Uganda. On the other hand, those levels were dominated by locally elected political leaders and the public were not motivated to participate due to cultural, social and economic barriers.

Community-based health programs established in the 1960s came from Brazilian educator Paulo Freire. In Freire's approach, problem-based methods must find a solution. As a result, an effort to utilize community participation approach is meaningful in terms of health. In addition, the theoretical foundation for community participation is clear and it leads a sustainable outcome for community-level health programs. Nevertheless, some leaders may abuse their position and undermine the legitimacy of health services by working toward their own interests. If they ignore community culture and traditions, it can be problematic for their policy context. Thus, it is important to facilitate health community participation efforts.

Meanwhile, literatures suggest that the successes of national health programs in China, Cuba, Sri Lanka, Tanzania, and Venezuela as well as in sub-national programs in Guatemala, India, Indonesia, Iran, Kenya, and Niger was by using community participation as a fundamental component of primary health care. It is well documented that community mobilization can bring about cost-effective and substantial reductions in mortality and improvements in the health of newborn, infants, children and mothers (Rosato et al, 2008). However, the levels of community participation were not measured in previous studies.

Much of previous research has proved that mothers' community participation in health programs can influence better child health. Nobles (2009) found a relationship between mothers' access to social capital via participation in community activities and their children's health in Indonesia. The results of the investigation showed children's health outcomes were related to maternal participation in community activities. In this research, community participation is measured simply as the number of community programs that are conducted within the community. This provided an estimate to participate, rather than actual participation that is related to child 
health.

It is noteworthy to state that community participation in health program by Rifkin (1991) indicated that community participation primarily existed at a health benefit and program activity levels. Besides, communities are not homogeneous. They are composed of different economic and social groups. In defining which groups are critical for participation to reach program goals, planners and agencies define groups which reflect program objectives. Based on personal observations, community participation in Iran is a means to increase the efficiency of the services provided by government or private sector not as an end itself. According to Tatar, (1996) Middle Eastern countries like Turkey have experienced community participation mainly because of the medical approach adopted by policy makers.

In Iran, the health system is established on district, province and national levels. A new national health system was intended based on what came to be recognized as Primary Health Care (PHC) approach. The natural reason of PHC with its characteristic stratification of services, well-established infrastructure, and emphasis on community participation and intersectional cooperation was considered to be a fixed basis for drawing-up rational policies and strategies. The Ministry of Health and Medical Education still remained vulnerable and the extension requires continuing political commitment and support (Shadpour, 1994).

Health care delivery in Iran in the past focused on health improvements by mobilizing communities to take preventive immunizations, but nowadays good health depends on individual life styles and involvement through empowering individuals and communities to change their attitudes and behaviors. Therefore, there is the need for health staff to give information about good health practices and to support efforts for individuals and communities to change their views about how health can be improved. People should take decisions and action in solving their own health problems and not rely on health personnel to provide all the answers. In the international scene, the success of Primary Health Care (PHC) in Iran has been well documented (Rifkin, 2005). A specific aspect of this success was the establishment of Community Health Workers known as Behvarz that connected community groups particularly in rural areas to local health units and health houses which subsequently changed the pattern of poor health (Shadpour, 2000).

Community participation focused on the prevention of communicable diseases, mother and child care, family planning and first aid. According to Solberg (2008), community participation in health research in Iran is an essential part of the country's health system after the 1979 Islamic Revolution. Furthermore, Community-based participatory research program started in 2003 and there are 18 Population Research Centers across the country, empowered with the necessary infrastructure for community participation. Many studies and interventions in the past 5 years, ranging from projects aiming to decrease rates of depression and tobacco consumption, to program promoting physical activity and good nutrition.

However, the issues of health education and community participation regarding breast cancer prevention are not similar to other activities included into PHC services, such as family planning in Iran. Giving attention to the participation of community residents can improve community responsibility to their health destiny. Therefore, the education of communities on diseases such as breast cancer, based on channels such as health workers, community leaders, health educators, health care professionals, teachers and women volunteers should be given high priority at the district, province and national levels. Additionally, there are a number of educational programs which have enhanced information on adolescent health, family planning, STIs, HIV/AIDS, and even sex issues to girls and boys. These programs are received by families and the authorities. In recent years, in addition to adolescent health problems, other issues have been assessed such as breast and uterine cancer screening, treatment of anemia, problems of aging, and osteoporosis (Malekafzali, 2004).

\section{Research methodology}

\subsection{Study area and respondents}

The study was carried out in metropolitan Tehran, Iran. Respondents were clients of gynecology wards in four participating hospitals in Tehran. After a sampling frame was made of all maternity hospitals affiliated to the Tehran University of Medical Sciences, four hospitals were chosen purposively. Although all the respondents in the locations were selected randomly for the interview, the study excluded women who had been given the diagnosis of breast cancer or any other breast disease. Health care generally and primary care specifically depends on the consolidation of personal health care and public health at the level of the local community (Van Weel, 2008). Thus, the researcher considered the contribution of women who complied with mammography in community-based cancer prevention program. 


\subsection{Study design and instrument}

Cross-sectional survey design is the essential approach in this study, and questionnaire was used in the collection of data from the identified women population at a particular point in time. This study analyzed the levels of women community participation in any community-based program related to breast cancer prevention based on community participation levels in health program by Rifkin (1991). A questionnaire interview is a data instrument. The questions related to participation levels were developed by the researcher based on Rifkin's perspective regarding participation levels in health programs and revised for content validity by an expert panel. Community participation components were measured dichotomous in nature. The scale was measured as yes or no (Yes $=1, \mathrm{No}=0$ ). Twenty items of community participation levels included in Rifkin's perspective of community participation in health programs was included. For further information, the frequency of voluntary participation in community-based programs were measured on a 3 point Likert scale from 1 to 3 (1="seldom", $2=$ "often", $3=$ "regularly") by asking women regarding their participation frequency. However, some studies measured voluntary participation by the number of programs in which participants participated. For example women participation in health programs emphasized children's growth by Nobles (2006).

The questionnaires were assessed for information quality and legitimacy, and corrections were made as needed. According to Garson (2009), the dimensions should have a Cronbach alpha of at least .70 to establish the reliability of the constructs. Based on the reliability alpha, the instrument revealed the Cronbach's alpha values in the pilot study and actual study as more than .70. Radzius (2001) noted that factor analysis does not account for dichotomous responses in some studies. Also, the sample sizes were relatively small, this may result in a unbalanced factor structure. Factor analysis techniques assume normal distribution of responses to each item on the questionnaire and are appropriate for questionnaires with multiple response options. Similarly, Baldwin (2005) documented that factor analysis with dichotomous data is controversial. As a result, in the current study factor analysis was not carried out for community participation levels. Community participation levels do not focus on a psychometric construct and just looks into people's participation in health programs regarding their health issue based on dichotomous responses ( $\mathrm{Yes}=1, \mathrm{No}=0$ ), as well as a small number of participants. The quantitative analyses included computerized data processing in a software program. Descriptive statistics were used to describe the demographic characteristics. Chi-square test $\left(\chi^{2}\right)$ was used to identify significant association between participation levels and demographic factors, as well as to understand significant connection between levels of participation in health programs and individual factors.

\section{Results}

A total of 86 women who participated in mammography were interviewed. In this study, selected demographic variables between two groups were compared using chi-square (Table 1), chi-square $\left(\chi^{2}\right)$ test revealed significant relationships between age, education, occupation and women community participation $(\mathrm{P} \leq 0.01)$. Also, the study showed that marital status and income were not statistically different between levell and level 2 among women who participated in the community based program.

Results proved that women who participated in any program regarding breast cancer prevention, were divided into two levels (benefit, activities) presented in table 2. By means of $\chi^{2}$ test there is a significant difference between women who were in only level 1(benefits) and women who were in level 2(activities); $\chi^{2}(1)=26.79$, $\mathrm{p} \leq 0.01$.

Moreover, because of the trend of the respondents in answering questions, the frequency of participation levels may have been overestimated. Thus, for further information, levels of voluntary participation in community-based program were measured on a 3 point Likert scale from 1to 3 (1="seldom", 2="often", $3=$ "regularly") by asking women regarding their participation (table 3.). Results confirmed participants in both levels (benefits and activity) did not participate regularly. Women who were only in level one admitted that their participation were seldom for every item related to level one (100\%), while $62.7 \%$ of women in level 2 acknowledged that they often participated as an audience in selected programs. For items related to level two (Activities), voluntary labor (73.2\%), contributed money or resource $(59.7 \%)$ and community meeting (50.7\%) were admitted by women who were in level 2 . The study acknowledged that they often participated in program activities, particularly those items mentioned. In fact, this study used Likert scale to reduce the overall response bias which exists in all face-to-face administration of surveys.

\section{Discussion}

In fact the current study claimed that community participation in breast cancer prevention was insignificant and just realized two levels. Similarly, literatures revealed that community participation in Iran have produced changes in health status in small-scale programs especially in public health centers. However, the study can be 
replicated on a national scale in the future. Because communities have different cultural values and historical roots, it is more useful to assess community participation as a process (Behdjat et al, 2009). Likewise, community participation in Iran has limited the first and sometimes the second levels of participation (participation in benefits and in the program activities). Higher levels (including community participation in implementing, monitoring and planning programs) have no specific programs in the health system (Shams, 2008).

Following participations in level one and two (benefits and activities), other studies documented by Bossert and Beauvais (2002) support the current study. The authors reported that some ventures in communities in Uganda enabled people to participate in health benefit and program activity levels. The authors stressed other levels of participation, as mainly through elected leaders. Researchers believe that in two levels of participation especially breast cancer issue, people must derive advantage by social demographic factors. Thus, planners and agencies should recognize women demographic characteristics in community participation regarding health, particularly community participation in community -based programs.

The present study revealed that women who participated in mammography screening have adequate knowledge about breast cancer prevention program run by some community based organizations such as breast cancer advocates, NGOs, work place health promotion program or public health centers in their districts because all of them have participated in some programs. However, their levels of participation were limited to two levels (Benefits and activities). Besides, it is not possible to present time preference, which is one of the conditions that needs to be met to ensure causality in cross sectional surveys (Kline, 1998). Therefore, the time of mammography utilization and women attendance in any health program cannot be properly envisioned in the current research. The results of this study suggest that for the development of women community participation in breast cancer prevention at various communities, policy maker should provide programs which are very specific for socio-demographic factors, behavioral, social and cultural attributes. If women are familiar with health issue such as breast cancer, they can participate actively in future control programs. Community participation in health programs has been found to be critical towards their success (Mlozi et al., 2006). It may be true that a greater level of participation tends to have knowledgeable people with regards to health issue.

Consistent with our results, Nobles (2006) found mothers' community participation was related to child's health. Mothers' program type achieved more participants including community meeting, women participation in association, and voluntary labor. Likewise, Sindato (2008) documented that majority of African in Urambo District of western Tanzania who had knowledge about tsetse flies and who knew a control technique were willing to contribute labor and money respectively. It means community awareness related to particular health issue aids community mobilization in health activities.

However, communities contributed to health programs mainly at the levels of benefits and activities in developing countries. Still, the researcher provided valuable information regarding the levels of women participation and its frequency in formal or informal programs on the subject of breast cancer prevention. Furthermore, in regards to the definition of sustainability related to community- based health programs, according to Bossert (1990)" the continuation of activities and benefits achieved during the project after the donor's funding has ceased." It means benefits and activities build the meaning of sustainability while decision making, monitoring, evaluation and implementation were yet governed by health care professionals. However, the lack of serious commitment might be a barrier in the sustainability of community-based control strategies (Sindato, 2008).

It is recommended that policy makers provided further education for women community participation in their own health, particularly in decision making process concerning health and wellbeing. Results of this study may apply in designing any such educational program to enhance women community participation and their awareness regarding breast cancer prevention which, in turn, can reduce mortality rates among women.

\section{Conclusion}

The current study presented the levels of community participation in community based program about breast cancer by women who have participated in mammography. Based on the findings of this study it can be concluded that, levels of women community participation are limited. But a community is empowered if its people are individually empowered (Jakarta Declaration 1997). Thus, the persistence of benefits and activities within the enormous heterogeneity of communities would motivate participation at a higher level provided that they are individually empowered. Consequently, the sustainability of the health programs can be facilitated by community participation in programs to cooperate with health care professionals even though it is limited at low levels. On the other hand, policy makers should find the mechanisms to facilitate public participation in decision 
making, monitoring, evaluation and implementation. However, Iranian community participation in health programs is dominated by health care professionals.

In order to promote community participation in breast cancer prevention, factors that influence women participation in community-based program need to be understood to provide guiding framework for the planning, implementation and evaluation at higher levels of community participation in health. Furthermore, health care professionals must evolve a practical framework for the sustainability of health programs to help promote programs regarding breast cancer prevention. To date, a comprehensive evaluation of Iranian women community participation and breast cancer prevention has not been undertaken. Finding will be useful, for this at risk population (women) with emphasis on their role in their own health development and its sustainability.

\section{References}

Baldwin, K. A.,Grinslade, M. S., Baer, L. C., Watts, P., Dinger, M. K., \& McCubbin, J. (2005). Research in Nursing \& Health, 28(5), 431-440.

Behdjat, H., Rifkin, S., Tarin, E., \& Sheikh, M. (2009). A new role for women health volunteers in urban Islamic republic of Iran. Eastern Mediterranean Health Journal, 15(5), 1165.

Bossert TJ, Beauvais JC. (2002). Decentralization of health systems in Ghana, Zambia, Uganda and the Philippines: a comparative analysis of decision space. Health Policy and Planning, 17:14-31.

Cohen, S., \& Syme, S. (1985). Social support and health. Toronto: Academic Press.

Freire, P. (1970, 1993). The Pedagogy of the Oppressed. Penguin: London.

House, J., Landis, K., \& Umberson, D. (1988). Social relationships and health. Science, 241, 540-545.

Jakarta declaration. (1997). The 4th International Conference on Health Promotion: New Players for a New Era, and the Jakarta declaration on leading health promotion into the 21st century. Jakarta, Indonesia.

Kapiriri, L., Norheim, O. F., \& Heggenhougen, K. (2003). Public participation in health planning and priority setting at the district level in Uganda. Health Policy and Planning, 18(2), 205.

Kline, R. B. (1998). Principles and practice of structural equation modeling. New York: Guilford Press.

Malekafzali, H. (2004). Population control and reproductive health in the Islamic republic of Iran. Archives of Iranian Medicine, 7(4), 247-250.

Mikkelsen, B. (1995). Methods for development work and research: A guide for practitioners. New Delhi: Sage.

Mlozi, M.R.S, Shayo, E.H., Senkoro, E.H., Mayala, B.K., Rumisha, S.F., Mutayoba, B., Senkondo, E., Maerere, A. \& Mboera, L.E.G. (2006). Participatory involvement of farming communities and public sectors in determining malaria control strategies in Mvomero District, Tanzania. Tanzania Health Research Bulletin, 8, 134-140.

Myezwa, H., \& M'kumbuzi, V. (2003). Participation in community based rehabilitation programs in zimbabwe: Where are we. Asia Pacific Disabil. Rehabil. J, 14(1), 18-29.

Nobles, J., \& Frankenberg, E. (2009). Mothers' community participation and child health. Journal of Health and Social Behavior, 50(1), 16-30.

Oakley, P. (1989). Community involvement in health development: An examination of the critical issues. Geneva: WHO.

Oakley, P. (1991). Projects with people: The practice of participation in rural development. Geneva:ILO.

Radzius, A., Moolchan, E. T., Henningfield, J. E., Heishman, S. J., \& Gallo, J. J. (2001). A factor analysis of the fagerstrom tolerance questionnaire. Addictive Behaviors, 26(2), 303-310.

Raeburn J, Rootman I. (1998). People centered health promotion. Chichester: John Wiley \& Sons.

Rifkin S. (1991). Community participation in maternal and child health/ family planning programs. Geneva: World Health Organization.

Rifkin S.B. (2005). Community Participation in Iran; A Report of a Consultancy undertaken on behalf of the World Health Organization (EMRO): November 5-18.

Rifkin, S. B. (1986). Lessons from community participation in health programs. Health Policy and Planning, 1(3), 240.

Rifkin, S. B. (1996). Paradigms lost: Toward a new understanding of community participation in health 
programs. Acta Tropica, 61(2), 79-92

Rosato, M., Laverack, G., Grabman, L. H., Tripathy, P., Nair, N., Mwansambo, C., et al. (2008). Community participation: Lessons for maternal, newborn, and child health. The Lancet, 372(9642), 962-971.

Shadpour, K. (1994). The PHC Experience in Iran. The Council for Expansion of PHC Networks, Ministry of Health and Medical Education, UNICEF, Teheran.

Shadpour, K. (2000). Primary health care networks in the Islamic Republic of Iran. Eastern Mediterranean Health Journal, 6:4:822-825.

Shams, B., Golshiri, P., Zamani, A., \& Pourabdian, S. (2008). Mothers' participation in improving growth and nutrition of the children: A model for community participation. Iranian J Publ Health, 37(2), 24-31.

Sindato, C., Kimbita, E., \& Kibona, S. (2008). Factors influencing individual and community participation in the control of tsetse flies and human African Trypanosomiasis in urambo district, tanzania. Tanzania Journal of Health Research, 10(1), 20.

Solberg, K. E. (2008). Iran engages local communities in health research. The Lancet, 372(9649), 1533.

Stone L. (1992). Cultural influences in community participation in health. Social Science and Medicine, 35: 409-17.

Tatar, M. (1996). Community participation in health care: The Turkish case. Social Science \& Medicine, 42(11), 1493-1500.

Van Weel, C., De Maeseneer, J., \& Roberts, R. (2008). Integration of personal and community health care. Lancet, 372(9642), 871-872.

Vuori, H. (1986). Community participation in primary health care a means or an end. In H. Vuori, \& J.E.F. Hastings, Patterns of community participation in primary health care. World Health Organization Regional Office for Europe, Copenhagen.

WHO. Declaration of Alma-Ata. Geneva: World Health Organization. (1978). [Online] Available: http://www.who.int/hpr/NPH/docs/ declaration Alma-Ata.

World Health Organization. (1991). Community involvement in health: Indicators. Copenhagen: W.H.O.

Zakus, J. D. L. (1998). Resource dependency and community participation in primary health care. Social Science Medicine, 46(4-5), 475-494. 
Table 1. Demographic Characteristics of respondents based on the levels of community participation in community-based program

\begin{tabular}{|c|c|c|c|c|c|c|c|}
\hline Demographic & aracteristics & $\begin{array}{r}\text { Lev } \\
n=19(22\end{array}$ & & $\begin{array}{r}\text { leve } \\
\mathbf{n}=67(77\end{array}$ & & $\chi^{2}$ & sig \\
\hline & & & & & & & \\
\hline$\overline{\text { Age }}$ & -40 & 21.1 & 4 & 23.9 & 16 & & \\
\hline & $41-45$ & 31.6 & 6 & 43.3 & 29 & 1465 & 002 \\
\hline & $46-50$ & 15.8 & 3 & 29.9 & 20 & 14.00 & .002 \\
\hline & $>51$ & 31.6 & 6 & 3.0 & 2 & & \\
\hline Education & Primary school & 21.1 & 4 & - & - & & \\
\hline & diploma & 36.8 & 7 & 6.0 & 4 & 3082 & $0 \cap 1$ \\
\hline & Graduate & 42.1 & 8 & 79.1 & 53 & 30.82 & .001 \\
\hline & postgraduate & - & - & 14.9 & 10 & & \\
\hline Marital Status & Married & 78.9 & 15 & 65.7 & 44 & & \\
\hline & Widow & 10.5 & 2 & 11.9 & 8 & 1.46 & .482 \\
\hline & Single & 10.5 & 2 & 22.4 & 15 & & \\
\hline Occupation & $\begin{array}{l}\text { Full time } \\
\text { Employee }\end{array}$ & 36.8 & 7 & 76.1 & 51 & & \\
\hline & $\begin{array}{l}\text { Part Time } \\
\text { Employee }\end{array}$ & 10.5 & 2 & 17.9 & 12 & 23.66 & .001 \\
\hline & $\begin{array}{l}\text { Unemployed or } \\
\text { Housewife }\end{array}$ & 52.6 & 10 & 6.0 & 4 & & \\
\hline Income & low & 10.5 & 2 & 1.5 & 1 & & \\
\hline & middle & 73.7 & 14 & 83.6 & 56 & 3.65 & .161 \\
\hline & high & 15.8 & 3 & 14.9 & 10 & & \\
\hline Insurance & public & 100.0 & 19 & 86.6 & 58 & 285 & 001 \\
\hline & private & - & - & 13.4 & 9 & 2.03 & .091 \\
\hline
\end{tabular}

Table 2. Levels of women participation in community-based programs $(\mathrm{n}=86)$

\begin{tabular}{lccccc}
\hline Levels & $\mathbf{n}$ & $\mathbf{( \% )}$ & $\boldsymbol{\chi}^{\mathbf{2}}$ & $\mathbf{d f}$ & $\mathbf{P}$ \\
\hline Level 2 (Activity) & 67 & 77.9 & 26.79 & 1 & 0.01 \\
Level 1 (Benefit) & 19 & 22.1 & & & \\
\hline
\end{tabular}


Table 3. The levels of women's community participation in breast cancer prevention programs and its frequency according to the respondents

\begin{tabular}{|c|c|c|c|c|c|c|}
\hline \multicolumn{2}{|c|}{ Items } & \multirow[b]{2}{*}{ Seldom } & \multicolumn{2}{|c|}{ Only Level 1} & \multicolumn{2}{|c|}{$\begin{array}{l}\text { Level } 1 \text { and } \\
\text { Level } 2\end{array}$} \\
\hline \multirow[t]{3}{*}{1} & \multirow{3}{*}{$\begin{array}{l}\text { I have participated as an audience in a community } \\
\text {-based awareness program about breast cancer } \\
\text { prevention in any where such as health center, } \\
\text { work place or NGOs. }\end{array}$} & & 19 & $100 \%$ & 25 & $\begin{array}{c}37.3 \\
\%\end{array}$ \\
\hline & & Often & & & 42 & $\begin{array}{c}62.7 \\
\%\end{array}$ \\
\hline & & Regularly & & & & \\
\hline \multirow[t]{3}{*}{2} & \multirow{3}{*}{$\begin{array}{l}\text { I have followed health care professional's } \\
\text { information which was mentioned in community } \\
\text {-based awareness program towards my health. }\end{array}$} & Seldom & 19 & $100 \%$ & 34 & $\begin{array}{c}50.7 \\
\%\end{array}$ \\
\hline & & Often & & & 33 & $\begin{array}{c}49.3 \\
\%\end{array}$ \\
\hline & & Regularly & & & & \\
\hline \multirow[t]{3}{*}{3} & \multirow[t]{3}{*}{$\begin{array}{l}\text { I have consulted with my doctor / health staff } \\
\text { regarding breast cancer prevention. }\end{array}$} & Seldom & 19 & $100 \%$ & 33 & $\begin{array}{c}49.3 \\
\%\end{array}$ \\
\hline & & Often & & & 34 & $\begin{array}{c}50.7 \\
\%\end{array}$ \\
\hline & & Regularly & & & & \\
\hline \multirow[t]{3}{*}{4} & \multirow[t]{3}{*}{$\begin{array}{l}\text { I have been informed about breast cancer } \\
\text { screening methods by health care staff. }\end{array}$} & Seldom & 19 & $100 \%$ & 33 & $\begin{array}{c}49.3 \\
\%\end{array}$ \\
\hline & & Often & & & 34 & $\begin{array}{c}50.7 \\
\%\end{array}$ \\
\hline & & Regularly & & & & \\
\hline \multirow[t]{3}{*}{5} & \multirow[t]{3}{*}{$\begin{array}{l}\text { I have participated as a member in a breast cancer } \\
\text { prevention program. }\end{array}$} & Seldom & & & 49 & $\begin{array}{c}73.2 \\
\%\end{array}$ \\
\hline & & Often & & & 18 & $\begin{array}{c}26.8 \\
\%\end{array}$ \\
\hline & & Regularly & & & & \\
\hline \multirow[t]{3}{*}{6} & \multirow{3}{*}{$\begin{array}{l}\text { I have participated as a speaker about breast } \\
\text { cancer prevention in any program related to health } \\
\text { center, work place or NGOs }\end{array}$} & Seldom & & & 67 & $100 \%$ \\
\hline & & Often & & & & \\
\hline & & Regularly & & & & \\
\hline \multirow[t]{3}{*}{7} & \multirow[t]{3}{*}{$\begin{array}{l}\text { I have participated as a volunteer in some breast } \\
\text { cancer prevention programs. }\end{array}$} & Seldom & & & 18 & $\begin{array}{c}26.8 \\
\%\end{array}$ \\
\hline & & Often & & & 49 & $\begin{array}{c}73.2 \\
\%\end{array}$ \\
\hline & & Regularly & & & & \\
\hline \multirow[t]{3}{*}{8} & \multirow{3}{*}{$\begin{array}{l}\text { I have given consultation, comment or information } \\
\text { to others about breast cancer prevention. }\end{array}$} & Seldom & & & 67 & $100 \%$ \\
\hline & & Often & & & & \\
\hline & & Regularly & & & & \\
\hline \multirow[t]{3}{*}{9} & \multirow{3}{*}{$\begin{array}{l}\text { I have met other members outside of program to } \\
\text { cooperate with them about breast cancer issue. }\end{array}$} & Seldom & & & 67 & $100 \%$ \\
\hline & & Often & & & & \\
\hline & & Regularly & & & & \\
\hline
\end{tabular}




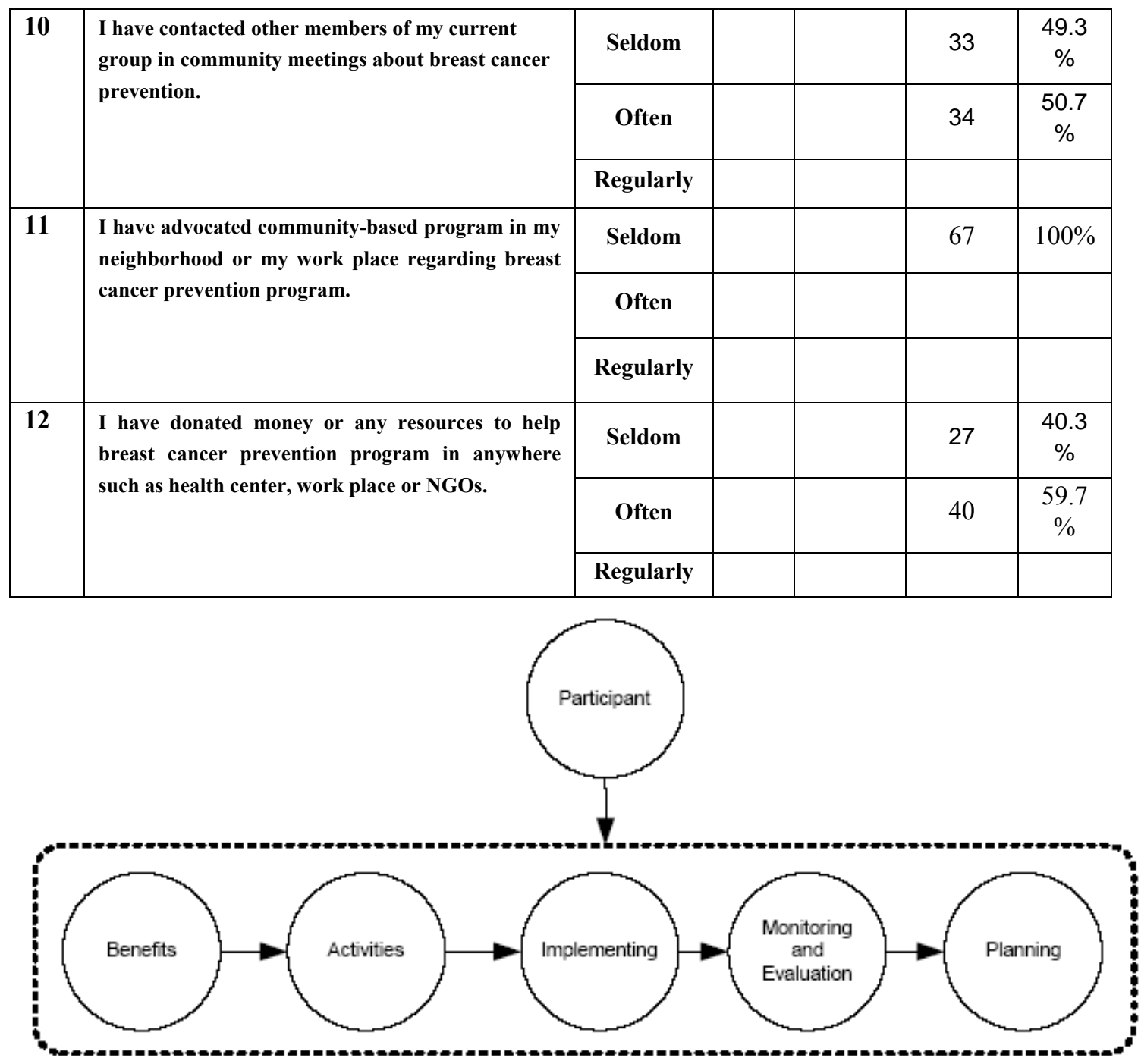

Figure 1. Community participation levels in health programs adapted from (Rifkin, 1991)

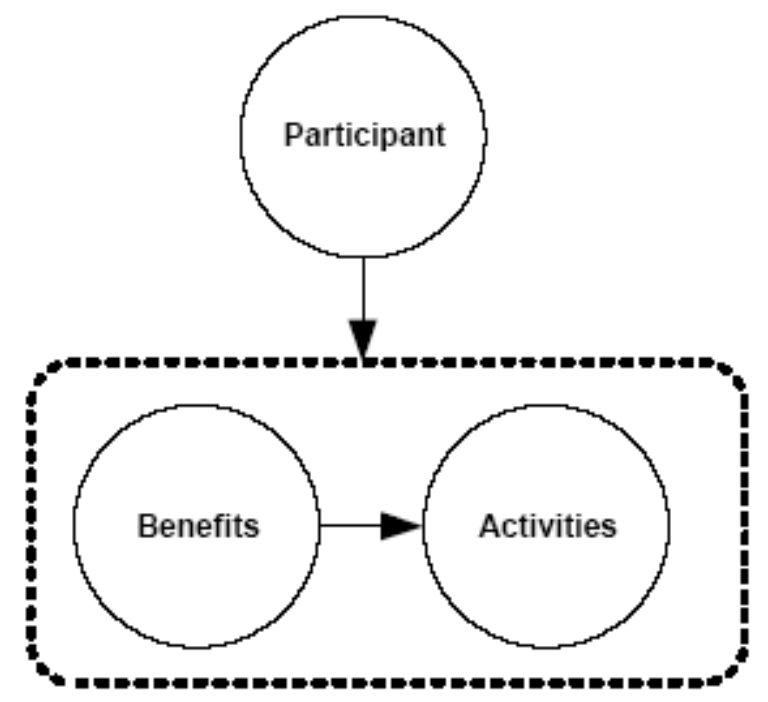

Figure 2. Women's community participation levels in health programs regarding breast cancer prevention in Iran 